\title{
Sophistication in Risk Management, Bank Equity, and Stability
}

This version: November 2009

\begin{abstract}
We investigate the question of whether sophistication in risk management fosters banking stability. We compare a simple banking system which uses an average rating with a sophisticated banking system in which banks are able to assess the default risk of entrepreneurs individually. Both banking systems compete for deposits, loans, and bank equity. While a sophisticated system rewards entrepreneurs with low default risks with low loan interest rates, a simple system acquires more bank equity and finances more entrepreneurs. Expected repayments in a simple system are always higher and its default risk may be lower. As an economy with a sophisticated banking system invests its funds more efficiently, there is a trade-off between efficiency and stability of a banking system.
\end{abstract}

Keywords: Financial intermediation, macroeconomic risks, risk management, risk premia, banking regulation, rating.

JEL Classification: D40, E44, G21 


\section{Introduction}

The popular view of banking regulation is that more sophistication in rating and risk management increases the stability of banking systems. This view has motivated the introduction of modern risk management techniques during the last decade. While sophisticated rating tools are well established in capital markets ${ }^{1}$, their application by commercial banks to credit markets is a more recent development. From the viewpoint of a single institution, it is clear that costless sophistication of risk management techniques will always be beneficial as it will allow an institution to price the risk of a loan more accurately. However, the extent to which this is beneficial for an economy as a whole when all banks adopt more sophisticated risk management techniques is a largely unresolved issue.

In this paper we argue that the systemic perspective may lead to conclusions which may significantly differ from the conclusions of a single institution. We investigate how the investment behavior of banks will affect the stability of the banking system with the introduction of more sophisticated rating techniques. We consider a competitive banking system in which banks offer their intermediation services to a population of entrepreneurs who have three investment opportunities for their initial wealth: a production project which is subject to macroeconomic risks, bank equity, or an alternative asset with an exogenously given return. Banks compete for equity and deposits and offer loans as delegated monitors. Risk premia on loans are determined by the equity market as banks need to offer sufficient returns in order to attract equity. We compare two polar cases, a simple and a sophisticated banking system. In the simple system banks are unable to distinguish between different production projects. They attribute the same default risk to each project such that each entrepreneur is in the same rating category. In the sophisticated system banks are able distinguish between different production projects. The rating categories are infinitely fine such that loan interest rates are adjusted to the individual default risk of an entrepreneur.

Our main findings are as follows. First, relative to the simple banking system which offers the same credit contract to all entrepreneurs, a sophisticated system adjusts loan interest rates to the default risk of the projects. This pricing in of risk reduces the demand for loans in the sophisticated system because fewer entrepreneurs with low-quality projects apply for loans. An economy with a sophisticated banking system therefore acquires less equity and finances fewer production projects.

\footnotetext{
${ }^{1} \mathrm{~A}$ large body of literature investigates the consequences of modern risk management techniques for capital markets which have risen dramatically over the last decades, cf. Carey \& Stulz (2006).
} 
Second, as simple banks attract more equity, their capital buffer against adverse macroeconomic productivity shocks is larger. Although sophisticated banks have higher average-quality projects, they may therefore be less capable of absorbing adverse productivity shocks. Third, aggregate repayments to the simple banking system are on average higher than to the sophisticated system. As a consequence, the default risk of the sophisticated banking system may be higher. Fourth, with a sophisticated banking system an economy invests more funds into the alternative asset. As on average, aggregate consumption in an economy with a simple banking system is lower, the economy with a sophisticated system invests its funds more efficiently. This shows that sophistication in rating may entail a tradeoff between stability and efficiency.

The approach of this paper is complementary to the work of Gehrig \& Stenbacka (2004) who show that uncoordinated screening behavior of competing financial intermediaries creates a financial multiplier and may be an independent source of fluctuations. In analyzing the systemic effects of screening devices, this paper contributes to the literature on screening by banks as surveyed, for example, in Freixas \& Rochet (2008). The focus of this paper is more on the consequences for market conditions and systemic defaults when banks introduce more sophisticated rating tools. An interesting question for future research is how the introduction of other sophisticated risk management techniques such as the securitization of bank loans and the use of derivative products affect systematic risks as discussed in Franke \& Krahnen (2006).

Our results are related to the literature on banking regulation. Comprehensive surveys with different emphases are given by Bhattacharya \& Thakor (1993), Dewatripont \& Tirole (1994), Hellwig (1994), Freixas \& Rochet (2008), or Bhattacharya, Boot \& Thakor (1998). Overall, we suggest that increased sophistication in rating ${ }^{2}$ as advocated in the new banking regulatory framework (Basel II) may produce unintended negative side effects. Indeed, the analysis of our paper indicates that increased sophistication in banking may create more instability in the long run.

The paper is organized as follows: In the next section we introduce the model and both types of banking systems. In Section 3 we examine simple banks, and in Section 4 we perform the mirror-image of the analysis for sophisticated banks. In Section 5 both systems are compared and our main results are presented. Section 6 concludes, formal proofs are relegated to the appendix.

\footnotetext{
${ }^{2}$ Krahnen \& Weber (2001) develop a comprehensive set of intuitive rating principles.
} 


\section{Model}

\subsection{Consumers and entrepreneurs}

We consider a two-period model with periods $t=1$ and $t=2$. The population of agents consists of a continuum indexed by $[0,1]$. Each agent has individual wealth $W$ in the first period. Agents are divided into two classes. One fraction of agents, indexed by $[0, \eta]$ with $0<\eta<1$, are potential entrepreneurs. The other fraction, indexed by $(\eta, 1]$, are consumers. Potential entrepreneurs and consumers differ in that only the former have access to investment technologies.

Throughout this paper, we assume that the deposit rate $r^{d}$ is equal to an exogenously given return $r_{A}>0$ of an alternative asset ${ }^{3}$, so that aggregate savings become $\bar{S}=S\left(r_{A}\right)$, where $\bar{S}<(1-\eta) W{ }^{4}$ The alternative asset may be thought of as an outside option, such as government bonds or investments in other sectors of the economy that are not modeled explicitly.

Potential entrepreneurs are assumed to be risk-neutral and to consume only in the second period. Each entrepreneur has to decide whether to invest in a production project that converts period-1 goods into period-2 goods, to provide bank equity for banks, or to invest her funds in the alternative asset with return $r_{A}$. The funds required for each production project are fixed at $W+I$, so that an entrepreneur must borrow $I$ additional units of the good from banks to undertake the production project. Entrepreneurs are heterogeneous in the quality of their production projects which depends on their index $i$. The quality parameter of entrepreneur $i$ is assumed to be private information. If an entrepreneur of type $i$ obtains additional resources $I$ and decides to invest, investment returns in the second period amount to

$$
y=q(1+i) f(W+I)
$$

where $f$ denotes a standard atemporal neoclassical production function and $q>0$ represents an exogenous macroeconomic productivity shock in the economy. Since $W$ and $I$ will remain fixed throughout the paper, we write $f=f(W+I)$. The distribution of shocks $q$ is assumed to be given by a continuous density function $h(q)$ with support on a compact interval $[\underline{q}, \bar{q}]$ with $0<\underline{q}<\bar{q}$.

\footnotetext{
${ }^{3}$ This assumption can also be justified by arbitrage opportunities banks would have in case $r^{d}<r_{A}$. Under such circumstances, banks could simply collect funds from consumers and invest them into the alternative asset. Granting loans could then become non-profitable and financial intermediation would break down.

${ }^{4}$ Aggregate savings may be derived from a standard intertemporal optimization problem.
} 
Entrepreneurs are price-takers and operate under limited liability. Given a loan interest rate $r^{c}$, the expected profit of an investing entrepreneur $i$ is

$$
\Pi\left(i, r^{c}\right):=\int_{\underline{q}}^{\bar{q}} \max \left\{q(1+i) f-I\left(1+r^{c}\right), 0\right\} h(q) d q .
$$

As in Stiglitz \& Weiss (1981), $\Pi\left(i, r^{c}\right)$ is non-decreasing in quality levels $i$ and nonincreasing in loan rates $r^{c}$. Denote by $g$ the expected return on equity banks offer to their potential equity holders. A risk-neutral entrepreneur with the quality parameter $i \in[0, \eta]$ will prefer to invest in the production project rather than into equity or the alternative asset if the return on the production project is expected to be larger than the return on either equity or the alternative asset, i.e., if

$$
\Pi\left(i, r^{c}\right) \geq W\left(1+\max \left\{g, r_{A}\right\}\right)
$$

We will assume that savings are never sufficient to fund all entrepreneurs. Since aggregate savings $\bar{S}=S\left(r_{A}\right)$ is bounded by $(1-\eta) W$, this condition takes the form

$$
(1-\eta) W<\eta I
$$

\subsection{Banking Sector}

Following Gersbach \& Wenzelburger (2004), we assume that depositors cannot observe the quality parameters of entrepreneurs and cannot verify whether or not an entrepreneur invests. The existence of such market frictions necessitates financial intermediation (see e.g. Hellwig 1994). These informational problems are alleviated by $n$ (commercial) banks, indexed by $j=1, \ldots, n(n>1)$ which monitor borrowers as delegated monitors in the sense of Diamond (1984). Their monitoring is assumed to be efficient in that they are able to secure both the investment of an entrepreneur and the liquidation value in case of default, cf. Gersbach \& Uhlig (2005).

To avoid that properties other than the ability to rate entrepreneurs determine the results, we make the same assumption regarding the competitive structure of the banking sector. First, both banking systems compete for equity and loans while facing a given deposit interest rate $r_{A}$. Each bank $j$ can offer deposit contracts $D\left(r_{A}\right)$, where $1+r_{A}$ is the repayment offered for one unit of resources.

Second, banks raise equity by issuing equity contracts. An equity contract entitles the holder to a share of dividends in proportion to the resources he has given to a particular bank. A bank becomes a legal entity and can only operate if it obtains a sufficiently 
large amount of equity. ${ }^{5}$ By providing equity, an entrepreneur becomes a shareholder of a bank. As entrepreneurs are risk neutral, so are banks. Third, both banking systems are perfectly competitive and the respective equilibrium values of equity will be determined by the supply of deposits and the demand for loans. As entrepreneurs are allowed to invest in the alternative asset, the expected return on bank equity has to be as least as high as the return of the alternative asset. However, since bank owners are risk neutral they will never diversify their loan portfolio by simultaneously investing in the safe alternative asset. In particular, risk-neutrality implies that a priori banks have no incentive to take on additional equity to invest into the alternative asset should they decide to finance entrepreneurs. For simplicity we assume that issuing equity is costless. This point will be discussed in more detail in Section 5 below.

Competition among banks determines the level of equity and loan interest rates. We distinguish between a simple and a sophisticated banking system which differ only in their ability to rate the quality of an entrepreneur's production project.

1. Simple Banking System. The essential feature of the simple banking system is that banks are unable to rate entrepreneurs individually and to adjust loan contracts to the quality parameter $i$ of an entrepreneur. Banks only have an average rating of entrepreneurs and offer all entrepreneurs the same loan contract $C\left(r^{c}\right)$, where $1+r^{c}$ is the repayment required from entrepreneurs for one unit of borrowed resources.

2. Sophisticated Banking System. In a sophisticated banking system, banks are able to rate each entrepreneur individually and to offer entrepreneur-specific loan contracts, denoted by $C\left(r_{i}^{c}\right)$, where $r_{i}^{c}$ is the loan interest rate demanded from an entrepreneur of type $i$.

In both banking systems, banks operate under unlimited liability and loans are only constrained by the available amount of equity and deposits. We assume throughout that aggregate uncertainty is canceled out when depositors and entrepreneurs randomly choose banks. ${ }^{6}$ As within each system all banks are identical, they will obtain the same amount of equity and deposits.

With these assumptions, the financial intermediation process in either system is as follows. Given $r_{A}$, banks in the first period offer equity contracts and loan contracts $r^{c}$

\footnotetext{
${ }^{5}$ Otherwise the legal entity is not founded as there are no owners.

${ }^{6}$ The exact construction of individual randomness so that this statement holds can be found in AlósFerrer (1999). We could also rely on the weaker forms of the strong law of large numbers developed in Al-Najjar (1995) and Uhlig (1996), where independence of individual random variables can be assumed and aggregate stability is the limit of an economy with finite characteristics.
} 
(simple banking) or a menu of loan contracts $\left\{r_{i}^{c}\right\}_{i=0}^{\eta}$ (sophisticated banking), respectively. Each bank $j$ obtains an amount of $d^{j}$ in equity and an equal share of deposits from consumers. Entrepreneurs decide which contracts to accept. Resources are exchanged. In the second period, funded entrepreneurs produce subject to a macroeconomic productivity shock and pay back loans with limited liability. Banks repay depositors and shareholders.

We are now ready to investigate the extent to which the ability to rate entrepreneurs reduces the vulnerability of a competitive banking system to non-performing loans. To this end, we will compare how equity develops in both types of banking systems. We are particularly interested in the distribution and downside risk of equity in the second period. It is intuitively clear that the lower accumulated equity is in period 2 , the more the stability of the banking sector is endangered.

\section{Competitive Equilibria for Simple Banks}

As all banks are assumed to be identical, the equilibrium conditions will be formulated for the whole banking system rather than for individual banks. If the total equity of the banking system is $d_{*}$, the amount of equity of an individual bank is $\frac{d_{*}}{n}$.

The amount of equity required by banks has to balance loan demand and has to meet capital adequacy rules. Let $i_{*} \in[0, \eta]$ be the equilibrium marginal quality level such that all entrepreneurs $i \in\left[i_{*}, \eta\right]$ invest in their production project and all entrepreneurs $i \in\left[0, i_{*}\right)$ either provide bank equity or invest in the alternative asset. If banks want to meet loan demand, their equity $d_{*}$ will have to satisfy

$$
\bar{S}+d_{*}=\left(\eta-i_{*}\right) I
$$

stating that loan demand equals supply. Second, the banking system is required to hold an equity level $d_{*}$ which satisfies the capital adequacy rule

$$
\frac{d_{*}}{\left(\eta-i_{*}\right) I} \geq \alpha
$$

where $0 \leq \alpha \leq 1$ is some small positive number (e.g. $\alpha=8 \%$ as in Basel I). The capital requirement (5) states that banks' equity has to lie above a prescribed percentage $\alpha$ of the credit volume $\left(\eta-i_{*}\right) I$. Inserting (4) into (5), we see that the minimum equity level the banking system needs in order to satisfy (5) is given by

$$
d_{\mathrm{reg}}=\frac{\alpha}{(1-\alpha)} \bar{S}
$$

In other words, $d_{\text {reg }}$ is the regulatory equity level banks must at least acquire in order to be allowed to operate. Since at most $i_{*}$ entrepreneurs will provide their equity, the 
resource constraints for equity of the banking system are amount to

$$
d_{\mathrm{reg}} \leq d_{*} \leq i_{*} W
$$

Using (4), the resource constraints (7) translate into two restrictions on the marginal quality level $i_{*}$, namely that $i_{*} \in[\underline{i}, \bar{i}]$ with $^{7}$

$$
\underline{i}:=\frac{\eta I-\bar{S}}{I+W} \quad \text { and } \quad \bar{i}=\eta-\frac{\bar{S}}{(1-\alpha) I} .
$$

Given $i_{*} \in[\underline{i}, \bar{i}]$, the fraction of entrepreneurs that are financed is $\left(\eta-i_{*}\right)$ while the remaining resources $i_{*} W-d_{*} \geq 0$ will be invested into the alternative asset. At least $\underline{i}$ entrepreneurs must provide their endowments for equity in order to meet (4) and rule out credit rationing. This boundary case $i_{*}=\underline{i}$ implies $d_{*}=\underline{i} W$ so that the fraction of entrepreneurs that is financed is maximal.

\subsection{Equilibrium Concept}

Before we introduce the equilibrium concept for a simple banking system, it is useful to imbed it into the broader context of the literature. As banks are unable to rate the quality of entrepreneurs individually, they face an adverse selection problem. However, as banks are able to secure the investment of entrepreneurs they finance, entrepreneurs with low-quality projects will be deterred from applying for loans. Thus, entrepreneurs sort themselves out into two groups: entrepreneurs with sufficiently high quality projects apply for loans, those with low-quality projects are better off by either providing equity for banks or investing into the alternative asset. This sorting mechanism guarantees the functioning of credit markets and prevents credit rationing in our equilibria. Sorting devices of this kind have been introduced in Bester $(1985,1987)$ following on from the seminal contribution by Stiglitz \& Weiss (1981).

Let $r^{d}=r_{A} \geq 0$ be the deposit interest rate. Banks receive funds $\bar{S}$ from consumers which have to be paid back with interest at the end of the second period. Given a return on equity $g$ and a loan interest rate $r^{c}$ which is charged to all investing entrepreneurs, (2) determines a marginal quality level $i_{*}$ so that all entrepreneurs $i<i_{*}$ provide equity or invest into the alternative asset and all entrepreneurs $i \geq i_{*}$ ask for loans at banks. Hence, aggregate loan demand of entrepreneurs becomes $\left(\eta-i_{*}\right) I$ so that repayments to the banking system $P=P\left(q, i_{*}, r^{c}\right)$ at the end of the second period are

$$
P\left(q, i_{*}, r^{c}\right)=\int_{i_{*}}^{\eta} \min \left\{q(1+i) f, I\left(1+r^{c}\right)\right\} \mathrm{d} i
$$

\footnotetext{
${ }^{7}$ We assume without loss of generality that $\underline{i}<\bar{i}$.
} 
and their equity level in the second period is

$$
G\left(q, i_{*}, r^{c}\right)=P\left(q, i_{*}, r^{c}\right)-\bar{S}\left(1+r_{A}\right)
$$

This equity level is payed out to the banks' shareholders. If

$$
\mathcal{R}\left(i, r^{c}\right):=\int_{\underline{q}}^{\bar{q}} \min \left\{q(1+i) f, I\left(1+r^{c}\right)\right\} h(q) \mathrm{d} q
$$

denotes the expected repayment of entrepreneur $i$ who has received a loan $I$ at the interest rate $r^{c}$, the expected repayments to the banking system are

$$
\mathbb{E}\left[P\left(\cdot, i_{*}, r^{c}\right)\right]=\int_{i_{*}}^{\eta} \mathcal{R}\left(i, r^{c}\right) \mathrm{d} i
$$

and the expected return on equity is

$$
g\left(i_{*}, r^{c}\right)=\frac{\mathbb{E}\left[P\left(\cdot, i_{*}, r^{c}\right)\right]-\bar{S}\left(1+r_{A}\right)-d_{*}}{d_{*}} .
$$

After these preparations, we may define a competitive equilibrium for a simple banking system with unlimited liability, that is, a system in which banks are fully accountable for possible losses. Intuitively, a competitive equilibrium is a marginal quality level, an equity level, and a loan interest rate $\left(i_{*}, d_{*}, r_{*}^{c}\right)$ such that

(i) it is optimal for banks to offer their intermediation services,

(ii) entrepreneurs take optimal investment decisions,

(iii) the market for loans is balanced.

\subsection{Existence of competitive equilibria}

Formally, a competitive equilibrium for a simple banking system with unlimited liability is defined as follows. ${ }^{8}$

\footnotetext{
${ }^{8}$ An equilibrium notion for a simple banking system with limited liability is found in Gersbach \& Wenzelburger (2004). While the interest rate margins in such systems will generally by larger, they are more complex to analyze. The qualitative results of this paper, however, should not be affected.
} 


\section{Definition 1}

Let $r_{A} \geq 0$ be given. A competitive equilibrium of a simple banking system which operates under unlimited liability is a triplet $\left(i_{*}, d_{*}, r_{*}^{c}\right)$ such that

$$
\begin{aligned}
\Pi\left(i_{*}, r_{*}^{c}\right) & =W\left[1+g\left(i_{*}, r_{*}^{c}\right)\right], \\
g\left(i_{*}, r_{*}^{c}\right) & \geq r_{A}, \\
\left(\eta-i_{*}\right) I & =\bar{S}+d_{*}, \\
d_{\mathrm{reg}} & \leq d_{*} \leq i_{*} W .
\end{aligned}
$$

The first two equilibrium conditions enforce a risk premium $r_{*}^{c}-r_{A}$ that accounts for the risk of loan losses. Specifically, equation (14) is the indifference condition for the marginal quality level $i_{*}$ which determines the demand for loans while equation (15) ensures that the return on bank equity is as least as high as the return of the alternative asset. ${ }^{9}$ Equation (16) is the equilibrium condition for loan demand and deposits already given in (4) and determines the required equity level. Condition (17) ensures that in equilibrium the banking system has enough equity to finance production projects and that it fulfills minimum capital requirements.

Note that if expected return on equity were lower than $r_{A}$, no equity would be supplied. In this case no bank could operate, since the minimum capital requirement in (17) were violated. If expected return on equity is strictly higher than $r_{A}$, then no entrepreneur will invest into the alternative asset, so that, as argued above, $i_{*}=\underline{i}$ and $d_{*}=\underline{i} W$. Writing $P_{*}(q):=P\left(q, i_{*}, r_{*}^{c}\right)$ for repayments to banks in a competitive equilibrium and inserting (16) into (13), the equilibrium condition (15) takes the form

$$
\mathbb{E}\left[P_{*}\right] \geq\left(\eta-i_{*}\right) I\left(1+r_{A}\right) .
$$

In equilibria with positive investment in the alternative asset the expected return on equity $g_{*}$ must be equal to $r_{A}$, i.e., (18) must hold with equality.

Existence and uniqueness of competitive equilibria are established in the following Proposition.

\section{Proposition 1}

Let $r_{A} \geq 0$ be given and suppose that $\Pi(\underline{i}, 0)>W\left(1+r_{A}\right)$. Then the following holds:

(i) If average output of the entrepreneurs with the boundary quality levels as given in (8) satisfies

$$
\frac{\mathbb{E}[q]\left(1+\frac{i+\eta}{2}\right) f}{W+I}<1+r_{A} \leq \frac{\mathbb{E}[q]\left(1+\frac{\bar{i}+\eta}{2}\right) f}{W+I},
$$

\footnotetext{
${ }^{9}$ Alternatively, this equation may be interpreted as a free-exit condition for banks, cf. Gersbach \& Wenzelburger (2006).
} 
then a simple banking system admits a unique competitive equilibrium $\left(i_{*}, d_{*}, r_{*}^{c}\right)$ with $g\left(i_{*}, r_{*}^{c}\right)=r_{A}$. Moreover, $d_{\mathrm{reg}}<d_{*}<i_{*} W$ so that the investment into the alternative asset is strictly positive.

(ii) If average output of the entrepreneur $\underline{i}$ satisfies

$$
\frac{\mathbb{E}[q]\left(1+\frac{i+\eta}{2}\right) f}{W+I} \geq 1+r_{A}
$$

then a simple banking system admits a unique competitive equilibrium $\left(\underline{i}, \underline{i} W, r_{*}^{c}\right)$ with $g\left(\underline{i}, r_{*}^{c}\right)>r_{A}$. No funds will be invested into the alternative asset.

The existence of equilibrium requires two restrictions on the average productivity of entrepreneurs. The first on requires that entrepreneur $\underline{i}$ is willing to invest in her production project at a zero loan interest rate. The second one is that average output of $\frac{\bar{i}+\eta}{2}$ is higher than the return of the alternative asset $r_{A}$. The condition on the average output of the entrepreneur $\frac{i+\eta}{2}$ then determines whether excess funds are invested into the alternative asset.

\subsection{Instability}

We are now in a position to calculate the default probability of a simple banking system. Using (10) and (13), equilibrium second-period equity of a simple banking system can be written as

$$
\begin{aligned}
G_{*}(q):=G\left(q, i_{*}, r_{*}^{c}\right) & =P_{*}(q)-\bar{S}\left(1+r_{A}\right) \\
& =P_{*}(q)-\mathbb{E}\left[P_{*}\right]+d_{*}\left(1+g_{*}\right),
\end{aligned}
$$

where $g_{*}=g_{*}\left(i_{*}, r_{*}^{c}\right)$ is expected return on equity in equilibrium. Hence expected secondperiod equity becomes

$$
\mathbb{E}\left[G_{*}\right]=d_{*}\left(1+g_{*}\right) .
$$

An entrepreneur with quality level $i$ defaults if she is unable to fully pay back her credit, that is, if

$$
I\left(1+r_{*}^{c}\right)>q(1+i) f .
$$

The entrepreneur with the lowest quality level who is not bankrupt after encountering the shock $q$ is given by

$$
i_{B}=i_{B}(q):= \begin{cases}\frac{I\left(1+r_{*}^{c}\right)}{q f}-1 & \text { if } q_{\mathrm{TB}} \leq q<q_{\mathrm{NB}}, \\ i_{*} & \text { if } q \geq q_{\mathrm{NB}},\end{cases}
$$


where

$$
q_{\mathrm{NB}}:=\frac{I\left(1+r_{*}^{c}\right)}{\left(1+i_{*}\right) f} \quad \text { and } \quad q_{\mathrm{TB}}:=\frac{I\left(1+r_{*}^{c}\right)}{(1+\eta) f} .
$$

If shocks are sufficiently large, i.e., $q \geq q_{\mathrm{NB}}$, then no entrepreneur defaults and aggregate losses of banks are zero. For shocks $q_{\mathrm{TB}} \leq q<q_{\mathrm{NB}}$, all investing entrepreneurs with quality levels $i_{*}<i<i_{B}(q)$ enter bankruptcy, whereas entrepreneurs with quality levels $i \geq i_{B}(q)$ pay back their loans fully. Finally, all entrepreneurs will enter bankruptcy if $q<q_{\mathrm{TB}}$ and losses are maximal.

It follows directly from (19) that second-period equity is on average positive, so that a simple banking system will not default on average. The probability of a system-wide default by banks can now be calculated as follows. An individual bank is bankrupt if second-period equity is negative. Due to the assumed symmetry of banks, this is equivalent to the condition $G_{*}(q)<0$ stating that the whole banking system is bankrupt. Aggregate losses of the banking system in equilibrium are formally defined as

$$
L_{*}(q):=\left(\eta-i_{*}\right) I\left(1+r_{*}^{c}\right)-P_{*}(q) \text {. }
$$

Since

$$
\mathbb{E}\left[L_{*}\right]-L_{*}(q)=P_{*}(q)-\mathbb{E}\left[P_{*}\right],
$$

it follows from (19) that the banking system defaults if

$$
L_{*}(q)>\mathbb{E}\left[L_{*}\right]+d_{*}\left(1+g_{*}\right)
$$

By (21) a necessary condition for the default of a bank is $q<q_{\mathrm{NB}}$. The default probability for banks can now be determined as follows.

\section{Proposition 2}

Under the hypotheses of Proposition 1, assume that

$$
L_{*}(\underline{q})>\mathbb{E}\left[L_{*}\right]+d_{*}\left(1+g_{*}\right)>L_{*}(\bar{q}),
$$

so that banks may default. Then there exists a unique marginal level $\underline{q}<q_{\text {crit }}<\bar{q}$ for macroeconomic shocks, such that the banking system defaults if and only if $q<q_{\text {crit }}$. The default probability is

$$
\pi_{\text {default }}:=\operatorname{Prob}\left(L_{*}(q)>\mathbb{E}\left[L_{*}\right]+d_{*}\left(1+g_{*}\right)\right)=\int_{\underline{q}}^{q_{\text {crit }}} h(q) \mathrm{d} q .
$$

Proposition 2 shows that banks default with positive probability as soon as the buffer $d_{*}\left(1+g_{*}\right)$ is too small to insure against negative macroeconomic shocks. Observe that $q_{\text {crit }}<q_{\mathrm{NB}}$. 
The preceding results allows us to characterize the default probability of the banking system in terms of the underlying exogenous parameters and distributions. The equation (24) is a value-at-risk formula for the banking system and for an individual bank. It can be interpreted in a different way. Suppose that $\pi_{\text {default }}$ is predetermined, e.g., by banking regulation. Equation (24) determines then the required equity level $d_{*}$ such that the default risk is equal to $\pi_{\text {default }}$.

\section{Competitive Equilibria for Sophisticated Banks}

\subsection{Equilibrium concept}

We turn to the other polar case in which banks are sophisticated in their rating abilities so that they are able to detect the quality level $i$ of an individual entrepreneur. They can thus determine the entrepreneur-specific default probability. We will assume that the banks' debt/equity ratios are the same across loans. ${ }^{10}$ Since the loan size $I$ is fixed, this implies that each loan is backed by the same amount of equity and deposits. Leaving all assumptions as stated at the outset unchanged, the key difference to the simple banking system now is the requirement that sophisticated banks charge an actuarially fair interest rate for each loan. To do so, let $\mathcal{R}\left(i, r_{i}^{c}\right)$, as defined in (11), be the expected repayment from an entrepreneur with quality level $i$ who has received a loan $I$ at the interest rate $r_{i}^{c}$. The highest possible average repayment of entrepreneur $i$ is

$$
\mathcal{R}\left(i, r_{i}^{c}\right)=\mathbb{E}[q](1+i) f
$$

which is attained for all loan-interest rates $r_{i}^{c} \geq \frac{\bar{q}(1+i) f}{I}-1$.

In requiring banks to charge actuarially fair loan-interest rates, average repayments to banks have to be equal across entrepreneurs. Given some fixed amount $R_{0}$ to be repayed by investing entrepreneurs, an actuarially fair interest rate $r_{i}^{c}$ for entrepreneur $i$ has to be such that

$$
\mathcal{R}\left(i, r_{i}^{c}\right)=R_{0} \quad \text { for all } i \in\left[i_{\text {low }}, \eta\right]
$$

where $0 \leq i_{\text {low }}<\eta$ denotes the entrepreneur with the lowest quality level who is able to repay the amount $R_{0}$ on average. An average repayment $R_{0}$, which is attainable at least for entrepreneurs with sufficiently high qualities, must therefore satisfy

$$
R_{0}<\mathbb{E}[q](1+\eta) f
$$

\footnotetext{
${ }^{10}$ This is in accordance with the capital requirements of the first Basel Accord.
} 
Since (11) is non-decreasing in quality levels, any interest rates $r_{i}^{c}$ satisfying (25) will have to be non-increasing for all $i \geq i_{\text {low }}$. Since all entrepreneurs $i<i_{\text {low }}$ will never attain $R_{0}$, we assume that $r_{i}^{c}=r_{i_{\text {low }}}^{c}$ for all $i \in\left[0, i_{\text {low }}\right]$. Sophisticated banks may thus reward high-quality entrepreneurs with low interest rates while making it unattractive for low-quality entrepreneurs to apply for loan contracts.

To see that expected return on equity is equal across investing entrepreneurs, suppose for a moment that all entrepreneurs above some quality level $i^{o} \geq i_{\text {low }}$ apply for loans. The credit volume then is $\left(\eta-i^{o}\right) I$ which must be balanced by total equity and deposits, so that $d^{o}+\bar{S}=\left(\eta-i^{o}\right) I$. The required amounts of equity and deposits per loan $I$ are $d^{o} /\left(\eta-i^{o}\right)$ and $\bar{S} /\left(\eta-i^{o}\right)$, respectively. Given $r_{i}^{c}$, the expected return $g^{o}\left(i, r_{i}^{c}\right)$ on equity $d^{o} /\left(\eta-i^{0}\right)$ for a loan granted to entrepreneur an $i \in\left[i^{o}, \eta\right]$ is then given

$$
g^{o}\left(i, r_{i}^{c}\right)=\frac{\left(\eta-i^{o}\right) \mathcal{R}\left(i, r_{i}^{c}\right)-\bar{S}\left(1+r_{A}\right)-d^{o}}{d^{o}}
$$

Using (25), we see that the returns on equity across entrepreneurs must be equal such that

$$
g^{o}\left(i, r_{i}^{c}\right)=g^{o}\left(i^{o}, r_{i^{o}}^{c}\right) \text { for all } i \in\left[i^{o}, \eta\right] .
$$

Observe that a loan to entrepreneur $i$ is profitable for banks only if $g^{o}\left(i, r_{i}^{c}\right)$ is greater than or equal to $r_{A}$.

Intuitively, a competitive equilibrium for a sophisticated banking system with unlimited liability is a list consisting of a marginal entrepreneur, an equity level, and a menu of loan interest rates

$$
\left\{i_{*}^{o}, d_{*}^{o},\left\{r_{*}^{c o}(i)\right\}_{i=0}^{\eta}\right\}
$$

where $r_{i}^{c}=r_{*}^{c o}(i), i \in[0, \eta]$ is the loan interest rate offered to entrepreneur $i$, such that

(i) it is optimal for banks to offer their intermediation services at actuarially fair interest rates,

(ii) entrepreneurs take optimal investment decisions,

(iii) the market for loans is balanced.

\subsection{Existence of sophisticated equilibria}

A competitive equilibrium with financial intermediation for a sophisticated banking system is formally defined as follows. 


\section{Definition 2}

Let $r_{A} \geq 0$ be given. A sophisticated (competitive) equilibrium of a sophisticated banking system is a list

$$
\left\{i_{*}^{o}, d_{*}^{o},\left\{r_{*}^{c o}(i)\right\}_{i=0}^{\eta}\right\}
$$

consisting of a marginal entrepreneur $i_{*}^{o}$, an equity level $d_{*}^{o}$ and a non-increasing loan interest rate function $r_{*}^{c o}(i), i \in[0, \eta]$, such that

$$
\begin{aligned}
\mathcal{R}\left(i, r_{*}^{c o}(i)\right) & =R\left(i_{*}^{o}, r_{*}^{c o}\left(i_{*}^{o}\right)\right), \quad i \in\left[i_{*}^{o}, \eta\right] \\
\Pi\left(i_{*}^{o}, r_{*}^{c o}\left(i_{*}^{o}\right)\right) & =W\left[1+g^{o}\left(i_{*}^{o}, r_{*}^{c o}\left(i_{*}^{o}\right)\right)\right], \\
g^{o}\left(i_{*}^{o}, r_{*}^{c o}\left(i_{*}^{o}\right)\right) & \geq r_{A} \\
\left(\eta-i_{*}^{o}\right) I & =\bar{S}+d_{*}^{o}, \\
d_{\mathrm{reg}} & \leq d_{*}^{o} \leq i_{*}^{o} W .
\end{aligned}
$$

Condition (27) states that on average banks must receive the same repayment on each loan. Condition (28) is the indifference condition for the marginal entrepreneur $i_{*}^{o}$. Since $\Pi\left(i, r^{c}\right)$ is increasing in quality levels $i$ and decreasing in interest rates $r^{c}$ locally around $\left(i_{*}^{o}, r^{c o}\left(i_{*}^{o}\right)\right)$ and $r_{*}^{c o}(i)$ is non-increasing in $i$, all entrepreneurs $i<i_{*}^{o}$ either provide equity or invest into the alternative asset, whereas all entrepreneurs $i \geq i_{*}^{o}$ apply for loans and invest into their production project. As before, (30) is the equilibrium condition in the loan market which determines the required equity level. Condition (31) guarantees that the required equity for banks is available and that the minimum capital requirement stated at the outset of the paper is satisfied.

Equation (29) requires banks' return on equity to be at least as high as the return of the alternative asset. If the expected return on equity were lower than $r_{A}$, no equity would be supplied. In this case no bank could operate, since the minimum capital requirement in (31) as stipulated at the outset of the paper were violated. If the expected return on equity is strictly higher than $r_{A}$, no entrepreneur will invest into the alternative asset, so that, as argued above, $d_{*}^{o}=\underline{i} W$. Using (26) we see that the equilibrium condition (29) takes the form

$$
\mathcal{R}\left(i_{*}^{o}, r_{*}^{c o}\left(i_{*}^{o}\right)\right) \geq\left[\frac{d_{*}^{o}+\bar{S}}{\eta-i_{*}^{o}}\right]\left(1+r_{A}\right)=I\left(1+r_{A}\right)
$$

In view of (27) this shows that the average repayment of each investing entrepreneur must be at least $I\left(1+r_{A}\right)$. In equilibria with positive investment in the alternative asset (32) must hold with equality because $g_{*}^{o}=r_{A}$.

The existence and uniqueness of sophisticated equilibria are established as follows. 


\section{Proposition 3}

Let $r_{A} \geq 0$ be given and suppose that $\Pi(\underline{i}, 0)>W\left(1+r_{A}\right)$. Then the following holds:

(i) If average output of the entrepreneurs with the boundary quality levels as given in (8) satisfies

$$
\frac{\mathbb{E}[q](1+\underline{i}) f}{W+I}<1+r_{A} \leq \frac{\mathbb{E}[q](1+\bar{i}) f}{W+I}
$$

then a sophisticated banking system admits a unique sophisticated equilibrium $\left\{i_{*}^{o}, d_{*}^{o},\left\{r_{*}^{c o}(i)\right\}_{i=0}^{\eta}\right\}$ with $1+i_{*}^{o}=\frac{(W+I)\left(1+r_{A}\right)}{\mathbb{E}[q] f}$ and $g^{o}\left(i_{*}^{o}, r_{*}^{c o}\left(i_{*}^{o}\right)\right)=r_{A}$. Moreover, $d_{\text {reg }}<d_{*}^{o}<i_{*}^{o} W$, so that investment into the alternative asset is strictly positive.

(ii) If average output of the entrepreneur $\underline{i}$ satisfies

$$
\frac{\mathbb{E}[q](1+\underline{i}) f}{W+I} \geq 1+r_{A},
$$

then a sophisticated banking system admits a unique sophisticated equilibrium $\left\{\underline{i}, \underline{i} W,\left\{r_{*}^{c o}(i)\right\}_{i=0}^{\eta}\right\}$ with $g^{o}\left(i_{*}^{o}, r_{*}^{c o}\left(i_{*}^{o}\right)\right)>r_{A}$. No funds will be invested into the alternative asset.

The essential characteristics of a sophisticated banking system is that investing entrepreneurs pay loan interest rates according to their individual default risk. In general, loan-interest rates for entrepreneurs with a positive default risk is monotonically decreasing with the quality of their production projects, whereby entrepreneurs without a default risk pay the same rate. This observation is formally stated in the following Corollary 1.

\section{Corollary 1}

(i) Loan interest rates $r_{*}^{c o}(i)$ are decreasing in quality levels $i \in\left[i_{*}^{o}, \eta\right]$ which satisfy

$$
\underline{q}(1+i) f<I\left[1+r_{*}^{c o}(i)\right]
$$

that is, for all entrepreneurs who face a positive default risk.

(ii) If there exists an entrepreneur $i_{\mathrm{NB}} \in\left[i_{*}^{o}, \eta\right]$ with

$$
\underline{q}\left(1+i_{\mathrm{NB}}\right) f=I\left[1+r_{*}^{c o}\left(i_{\mathrm{NB}}\right)\right],
$$

so that all entrepreneurs $i \geq i_{N B}$ have zero default risk, then loan interest rates are constant for all $i \in\left[i_{\mathrm{NB}}, \eta\right]$.

Observe that since in equilibria with positive investment into the alternative asset (32) holds with equality, the loan-interest rate for entrepreneurs without default risk is $r_{A}$. In this case banks receive positive interest rate margins only for entrepreneurs with positive default risks. 


\subsection{Instability}

Similar to the case of simple banking, we can derive the default probability of an individual bank, which is equal to the probability of a system-wide collapse of the banking system. Aggregate repayments to banks in an sophisticated equilibrium are

$$
P_{*}^{o}(q)=\int_{i_{*}^{o}}^{\eta} \min \left\{q(1+i) f, I\left[1+r_{*}^{c o}(i)\right]\right\} \mathrm{d} i .
$$

Taking expectations and using (25) and (26), the expected (aggregate) repayments in a sophisticated equilibrium are

$$
\mathbb{E}\left[P_{*}^{o}\right]=\int_{i_{*}^{o}}^{\eta} \mathcal{R}\left(i, r_{*}^{c o}(i)\right) \mathrm{d} i=d_{*}^{o}\left(1+g_{*}^{o}\right)+\bar{S}\left(1+r_{A}\right),
$$

where $g_{*}^{o}=g^{o}\left(i_{*}^{o}, r_{*}^{c o}\left(i_{*}^{o}\right)\right)$ denotes the expected return on equity in equilibrium. This implies that second-period equity of the sophisticated system in equilibrium is

$$
\begin{aligned}
G_{*}^{o}(q) & :=P_{*}^{o}(q)-\bar{S}\left(1+r_{A}\right) \\
& =P_{*}^{o}(q)-\mathbb{E}\left[P_{*}^{o}\right]+d_{*}^{o}\left(1+g_{*}^{o}\right) .
\end{aligned}
$$

Taking expectations, expected second-period equity becomes

$$
\mathbb{E}\left[G_{*}^{o}\right]=d_{*}^{o}\left(1+g_{*}^{o}\right)
$$

A value-at-risk formula for a sophisticated banking system is obtained as follows. Aggregate losses of the sophisticated system are formally defined by

$$
L_{*}^{o}(q)=\int_{i_{*}^{o}}^{\eta} I\left[1+r_{*}^{c o}(i)\right] d i-P_{*}^{o}(q) .
$$

Inserting (37) into (35) yields

$$
G_{*}^{o}(q)=\mathbb{E}\left[L_{*}^{o}\right]-L_{*}^{o}(q)+d_{*}^{o}\left(1+g_{*}^{o}\right)
$$

The default condition for an individual bank and for the banking system is $G_{*}^{o}(q)<0$ which, using (38), takes the form

$$
L_{*}^{o}(q)>\mathbb{E}\left[L_{*}^{o}\right]+d_{*}^{o}\left(1+g_{*}^{o}\right)
$$

It can readily be seen from (38) that the future equity of the banking system is positive for sufficiently high shocks $q$. It follows from $(37)$ that $L_{*}^{o}(q)$ is decreasing in $q$. Therefore, the following proposition is proven analogously to Proposition 2. 


\section{Proposition 4}

Under the hypotheses of Proposition 3, assume that

$$
L_{*}^{o}(\underline{q})>\mathbb{E}\left[L_{*}^{o}\right]+d_{*}^{o}\left(1+g_{*}^{o}\right)>L_{*}^{o}(\bar{q}),
$$

so that banks may default. Then there exists a unique critical level $\underline{q}<q_{\text {crit }}^{o}<\bar{q}$ for macroeconomic shocks, such that a sophisticated banking system defaults if, and only if, $q<q_{\text {crit }}^{o}$. The default probability is

$$
\pi_{\text {default }}^{o}:=\operatorname{Prob}\left(L_{*}^{o}(q)>\mathbb{E}\left[L_{*}^{o}\right]+d_{*}^{o}\left(1+g_{*}^{o}\right)\right)=\int_{\underline{q}}^{q_{\text {crit }}^{o}} h(q) \mathrm{d} q .
$$

Similar to the case of a simple banking system, (40) is a value-at-risk formula for a sophisticated banking system. Proposition 4 states that banks default with positive probability as soon as the buffer $d_{*}^{o}\left(1+g_{*}^{o}\right)$ is too small to buffer negative macroeconomic shocks.

\section{Comparison of the two Systems}

For a comparison of the two banking systems, let us first consider the special case in which no entrepreneur defaults. In the simple banking system, this requires $\underline{q}\left(1+i_{*}\right) f \geq I\left(1+r_{*}^{c}\right)$. and hence

$$
\mathcal{R}\left(i, r_{*}^{c}\right)=I\left(1+r_{*}^{c}\right) \quad \text { for all } i \in\left[i_{*}, \eta\right] .
$$

In equilibria with positive investment into the alternative asset it follows from (18) that $r_{*}^{c}=r_{A}$. Using the equilibrium condition (14), we see that $i_{*}=i_{*}^{o}$. Hence the equilibrium condition (28) is satisfied and Corollary 1 implies

$$
r_{*}^{c o}(i)=r_{*}^{c}=r_{A} \quad \text { for all } i \in\left[i_{*}^{o}, \eta\right]
$$

This shows that the simple and the sophisticated banking system charge the same loaninterest rates and finance the same fraction of entrepreneurs. ${ }^{11}$ It is straightforward to infer from (28) that this situation can only occur if $\frac{q}{\mathbb{E}[q]} \geq \frac{I}{W+I}$.

\subsection{Interest rates, equity, and stability}

We assume throughout the remainder of the paper that $\frac{q}{\mathbb{E}[q]}<\frac{I}{W+I}$ so that entrepreneurial bankruptcies are possible. To ensure that both systems admit equilibria with positive default risks for entrepreneurs, the following assumption is made.

\footnotetext{
${ }^{11} \mathrm{~A}$ similar argument applies for equilibria without investment into the alternative asset.
} 


\section{Assumption 1}

(i) Entrepreneur $\underline{i}$ applies for a loan for a zero interest rate, i.e, if $\Pi(\underline{i}, 0)>W\left(1+r_{A}\right)$.

(ii) The average productivity of entrepreneur $\bar{i}$ satisfies $\frac{\mathbb{E}[q](1+\bar{i}) f}{(W+I)} \geq 1+r_{A}$.

(iii) The default risk of investing entrepreneurs is positive in the simple banking system, that is, $\frac{q}{\mathbb{E}[q]}<\frac{I}{W+I}$.

We begin by comparing the capability of the two systems to finance entrepreneurs and attract equity.

\section{Theorem 1}

Let the hypotheses of Assumption 1 be satisfied and suppose $i_{*}^{o}>\underline{i}$. Then the following properties hold:

$$
\text { (i) } i_{*}<i_{*}^{o}, \quad(\text { ii }) \quad d_{*}>d_{*}^{o}, \quad(\text { iii }) \quad i_{*} W-d_{*}<i_{*}^{o} W-d_{*}^{o} .
$$

The intuition for Theorem 1 is the following. By charging actuarially fair interest rates, sophisticated banks make it less attractive for low-quality entrepreneurs to apply for loans. They finance fewer production project than simple banks, i.e. $i_{*}<i_{*}^{o}$, and therefore need less equity implying $d_{*}^{o}<d_{*}$. As a consequence, with a sophisticated banking system more resources are invested in the alternative asset.

If the average productivity of entrepreneur $\underline{i}$ is greater than the safe return $1+r_{A}$, then the return on equity is greater than $r_{A}$ in both systems. In this case it is not profitable to invest into the alternative asset such that both systems accumulate the same amount of equity $\underline{i} W$, where $i_{*}=i_{*}^{o}=\underline{i}$. The following theorem now shows that the simple banking system earns a higher expected return on equity than a sophisticated system if both system do not invest into the alternative asset.

\section{Theorem 2}

Let the hypotheses of Assumption 1 be satisfied and suppose $i_{*}^{o}=i_{*}=\underline{i}$. Then the return on equity in the simple banking system is higher than the expected return on equity in the sophisticated system, that is, $g\left(\underline{i}, r_{*}^{c}\right)>g^{o}\left(\underline{i}, r_{*}^{c o}(\underline{i})\right)$.

The underlying reason for these two results is provided by the next theorem which compares the loan interest rate in the simple banking system with the menu of loan interest rates in a sophisticated system.

\section{Theorem 3}

Let the hypotheses of Assumption 1 be satisfied and assume, in addition, that both banking systems either do invest $\left(i_{*}^{o}>i_{*}>\underline{i}\right)$, or do not invest into the alternative asset 
$\left(i_{*}^{o}=i_{*}=\underline{i}\right)$. Then there exists $i_{\mathrm{ER}} \in\left(i_{*}^{o}, \eta\right)$ with

$$
\begin{aligned}
& \text { (i) } \quad r_{*}^{c}<r_{*}^{c o}(i), \quad i \in\left[0, i_{\mathrm{ER}}\right), \\
& (i i) \quad r_{*}^{c}=r_{*}^{c o}\left(i_{\mathrm{ER}}\right), \\
& \text { (iii) } r_{*}^{c}>r_{*}^{c o}(i), \quad i \in\left(i_{\mathrm{ER}}, \eta\right] .
\end{aligned}
$$

Theorem 3 shows that charging actuarially fair interest rates rewards high-quality borrowers with lower rates and penalizes intermediate-quality borrowers with higher rates. The effect is reflected by equation (32) which shows that the net present values of production projects financed by sophisticated banks are equal across entrepreneurs and zero in equilibria with investment in the alternative asset. By contrast, Theorem 3 with (18) implies that the net present values of production projects financed by simple banks are negative for intermediate-quality entrepreneurs $i<i_{\mathrm{ER}}$ and positive for high-quality entrepreneurs $i>i_{\mathrm{ER}}$. By requiring the same net present value across loans, sophisticated banks eliminate cross-subsidization between borrowers. Sophistication in rating, therefore, has distributional effects: high-quality entrepreneurs benefit while intermediatequality entrepreneurs are worse off.

It is straightforward to see that second-period equity of the simple banking system is on average higher than in the sophisticated system. By comparing (20) with (36), we infer either from Theorem 1 that first-period equity is higher while the return on equity is equal or from Theorem 2 that the return on equity is higher while first-period equity is equal. This yields the following result.

\section{Proposition 5}

Under the hypotheses of Assumption 1, expected second-period equity in the simple banking system is higher than in the sophisticated system and expected repayments to the simple banking system is higher than expected repayments to the sophisticated system, that is,

$$
\mathbb{E}\left[P_{*}\right]-\mathbb{E}\left[P_{*}^{o}\right]=\mathbb{E}\left[G_{*}\right]-\mathbb{E}\left[G_{*}^{o}\right]=d_{*}\left(1+g_{*}\right)-d_{*}^{o}\left(1+g_{*}^{o}\right)>0
$$

The default probabilities of the two banking systems are compared next. Let

$$
P_{*}(q)-P_{*}^{o}(q)=\int_{i_{*}}^{i_{*}^{o}} \min \left\{q(1+i) f, I\left(1+r_{*}^{c}\right)\right\} \mathrm{d} i+\int_{i_{*}^{o}}^{\eta} z(i, q) \mathrm{d} i,
$$

where

$$
z(i, q):=\min \left\{q(1+i) f, I\left(1+r_{*}^{c}\right)\right\}-\min \left\{q(1+i) f, I\left[1+r_{*}^{c o}(i)\right]\right\} .
$$

The first term on the r.h.s. of (42) reflects the difference in repayments that can be attributed to additional loans granted under a simple banking system, that is, a positive 
volume effect. The second term on the r.h.s. of (42) is the price effect of the differences in repayments. Under the hypotheses of Theorem 3 , there exists a quality level $i_{\mathrm{ER}} \in\left(i_{*}^{o}, \eta\right)$ such that $r_{*}^{c o}\left(i_{\mathrm{ER}}\right)=r_{*}^{c}$. Since the default risk for investing entrepreneurs is positive, $r_{*}^{c}>r_{A}$. This implies that there must exist a critical shock $q_{\mathrm{ER}}>\underline{q}$ such that

$$
q_{\mathrm{ER}}\left(1+i_{\mathrm{ER}}\right) f=I\left(1+r_{*}^{c}\right)=I\left[1+r_{*}^{c o}\left(i_{\mathrm{ER}}\right)\right]
$$

For the shock $q_{\mathrm{ER}}$ entrepreneurs with quality levels $i \geq i_{\mathrm{ER}}$ fully meet their repayment obligations in both systems. This implies that $z\left(i, q_{\mathrm{ER}}\right) \geq 0$ for $i \geq i_{\mathrm{ER}}$. On the other hand, in both systems all entrepreneurs $i<i_{\mathrm{ER}}$ default for the shock $q_{\mathrm{ER}}$. Hence, $z\left(i, q_{\mathrm{ER}}\right)=0$ for $i<i_{\mathrm{ER}}$. In view of (19) and (35), this implies that

$$
G_{*}(q)-G_{*}^{o}(q)=P_{*}(q)-P_{*}^{o}(q)>0 \quad \text { for all } q \in\left[\underline{q}, q_{\mathrm{ER}}\right) .
$$

The simple banking system thus outperforms the sophisticated system for adverse shocks

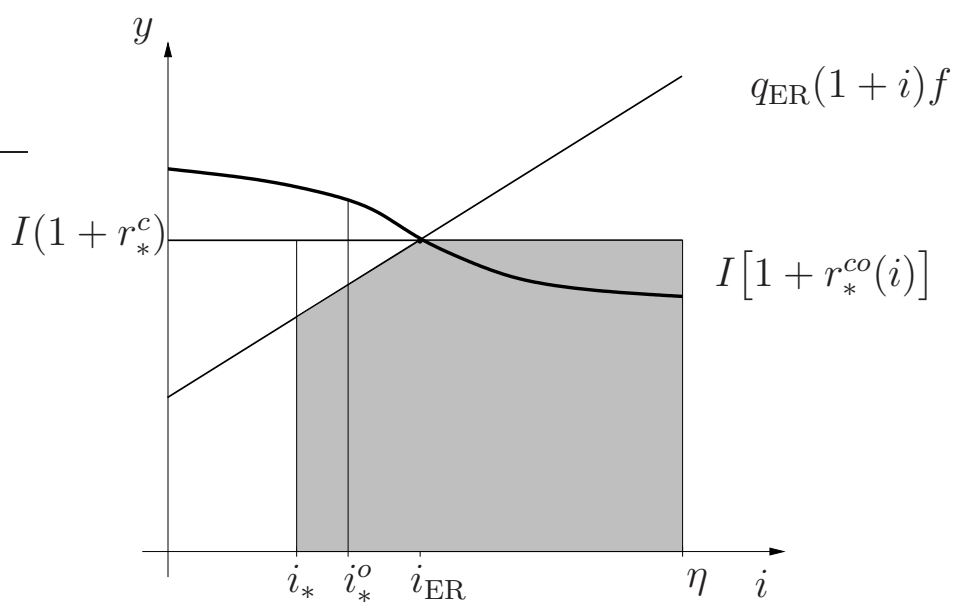

Figure 1: Repayments of entrepreneurs.

by accumulating more second-period equity for low shocks. This result is illustrated in Figure 1. The gray area of this figure describes the repayments to the simple banking system encountering the shock $q_{\mathrm{ER}}$. As can be seen from the figure, the repayments to the sophisticated system are lower for at least all shocks $q \leq q_{\mathrm{ER}}$. Formally, the result is summarized in the following proposition.

\section{Proposition 6}

Under the hypotheses of Assumption 1, there exists a shock $q_{\mathrm{BE}} \geq q_{\mathrm{ER}}$ with $q_{\mathrm{ER}}$ as given in (44), such that

$$
G_{*}(q)>G_{*}^{o}(q) \text { for all } q \in\left[\underline{q}, q_{\mathrm{BE}}\right)
$$


Proposition 6 states that the simple banking system accumulates more equity than the sophisticated system for all shocks below a break-even value $q_{\mathrm{BE}}$. It thus has a better capacity to absorb adverse macroeconomic shocks. It is interesting to note that the introduction of sophistication in rating to an economy may therefore create a positive default risk when $G_{*}(\underline{q})>0>G_{*}^{o}(\underline{q})$. While the simple system will never default if $G_{*}(\underline{q})>0$, the default probability of the sophisticated system is positive because $G_{*}^{o}(\underline{q})<$ 0 .

There are two cases, $q_{\mathrm{BE}} \geq \bar{q}$ and $q_{\mathrm{BE}}<\bar{q}$. In the first case the simple banking system outperforms the sophisticated system for all shocks. Its default probability $\pi_{\text {default }}$ is then lower than the default probability of the sophisticated system $\pi_{\text {default }}^{o}$. As for the second case, assume for simplicity that $G_{*}^{o}(q)>G_{*}(q)$ for all $q_{\mathrm{BE}}<q \leq \bar{q}$ such that repayments in the sophisticated system are higher than in a simple system for all sufficiently high shocks. Since in both systems all entrepreneurs repay for sufficiently high shocks, a sufficient condition for such a $q_{\mathrm{BE}}$ to exist is

$$
\int_{i_{*}^{o}}^{\eta} I\left[1+r_{*}^{c o}(i)\right] \mathrm{d} i>\left(\eta-i_{*}\right) I\left(1+r_{*}^{c}\right)
$$

such that repayments to sophisticated banks are higher than to simple banks if no entrepreneur defaults. The next theorem now compares default probabilities of the two

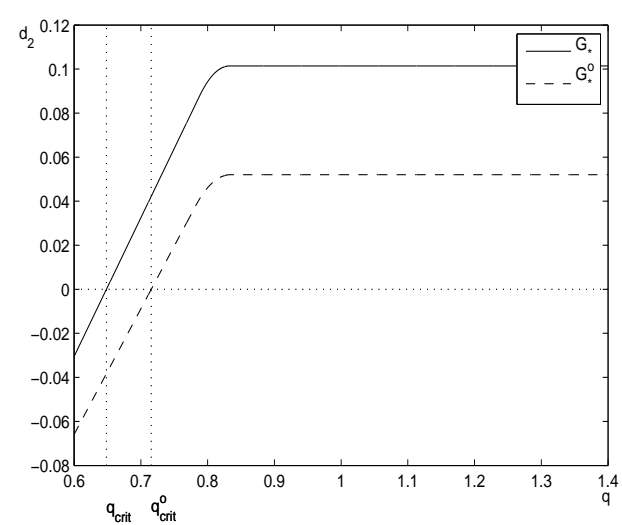

(a) Second period equity.

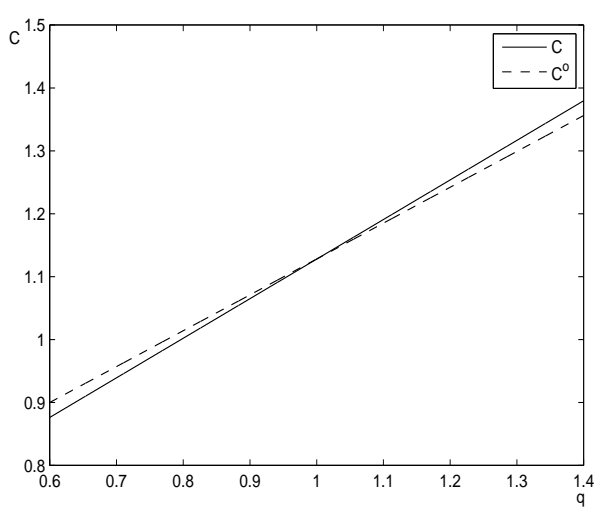

(b) Aggregate consumption.

Figure 2: Comparison of two banking systems, uniformly distributed shocks.

banking systems.

\section{Theorem 4}

Let the hypotheses of Assumption 1 be satisfied and assume, in addition, that the probability density be strictly positive, i.e., $h(q)>0$ for all $q \in[\underline{q}, \bar{q}]$. 
(i) Let $q_{\mathrm{BE}}$ be given by Proposition 6 and suppose

$$
G_{*}^{o}\left(q_{\mathrm{BE}}\right)=P_{*}^{o}\left(q_{\mathrm{BE}}\right)-\bar{S}\left(1+r_{A}\right)>0
$$

Then the default probability of the simple banking system is lower than the default probability of the sophisticated system, i.e., $\pi_{\text {default }}<\pi_{\text {default }}^{o}$.

(ii) Suppose that there exists $q_{\mathrm{BE}}<\bar{q}$ such that

$$
G_{*}^{o}(q)>G_{*}(q) \text { for all } q>q_{\mathrm{BE}}
$$

and

$$
G_{*}^{o}\left(q_{\mathrm{BE}}\right)=P_{*}^{o}\left(q_{\mathrm{BE}}\right)-\bar{S}\left(1+r_{A}\right)<0 .
$$

Then the default probability of the simple banking system is higher than the default probability of the sophisticated system, i.e., $\pi_{\text {default }}>\pi_{\text {default }}^{o}$.

Theorem 4 (i) is illustrated with Figure 2(a) for uniformly distributed shocks. ${ }^{12}$ The graph of the function $G_{*}^{o}$ lies entirely below the graph of $G_{*}$. Thus the default probability of the simple banking system is lower than the default probability of the sophisticated system. It follows from the respective equilibrium conditions (18) and (32) that in either system a change in aggregate savings $\bar{S}$, say, due to a chance in consumers' endowments, will only affect its equilibrium equity levels whereas loan interest rates and credit volumes remain unaltered. The amount of banks' liabilities may thus determine which default probability is higher.

\subsection{Efficiency}

In this section we will show that an economy with a sophisticated banking system will allocate its resources more efficiently than an economy with a simple banking system. We will do so by comparing aggregate consumption in the two economies in response to a common shock. Aggregate consumption of an economy with a simple banking system in response to the shock $q$ is

$$
C(q)=\int_{i_{*}}^{\eta} \max \left\{q(1+i) f-I\left(1+r_{*}^{c}\right), 0\right\} \mathrm{d} i+P_{*}(q)+\left(i_{*} W-d_{*}\right)\left(1+r_{A}\right)
$$

\footnotetext{
${ }^{12}$ Numerical details of the example are available upon request. We have not been able to find an example with uniformly distributed shocks that illustrates Theorem 4 (ii).
} 
and consists of aggregate consumption of investing entrepreneurs, repayments to banks, and repayments to entrepreneurs who invested into the safe asset. Observe that adding the first two terms in (46) gives

$$
Y(q)=q f \int_{i_{*}}^{\eta}(1+i) \mathrm{d} i
$$

which is aggregate output of entrepreneurial production in response to the shock $q$. Thus aggregate consumption consists of aggregate output and the gross return from the investment into the safe asset:

$$
C(q)=Y(q)+\left(i_{*} W-d_{*}\right)\left(1+r_{A}\right)
$$

Similarly, aggregate consumption of an economy with a sophisticated banking system is

$$
C^{o}(q)=\int_{i_{*}^{o}}^{\eta} \max \left\{q(1+i) f-I\left(1+r_{*}^{c o}(i)\right), 0\right\} \mathrm{d} i+P_{*}^{o}(q)+\left(i_{*}^{o} W-d_{*}^{o}\right)\left(1+r_{A}\right) .
$$

Adding the first two terms in (47) gives

$$
C^{o}(q)=Y^{o}(q)+\left(i_{*}^{o} W-d_{*}^{o}\right)\left(1+r_{A}\right)
$$

where

$$
Y^{o}(q)=q f \int_{i_{*}^{o}}^{\eta}(1+i) \mathrm{d} i
$$

is aggregate output of entrepreneurial production in response to a shock $q$. From Theorem 1 we have $i_{*}^{o}>i_{*}$ which leads to

$$
Y(q)>Y^{o}(q) \text { for all } q \in[\underline{q}, \bar{q}]
$$

This implies that sophisticated banks will reduce investment in entrepreneurial production. On the other hand, Theorem 1 also states that sophisticated banks invest more funds into into the alternative asset. The next result now shows that placing more funds into the alternative asset is more efficient.

\section{Theorem 5}

Let hypotheses of Assumption 1 be satisfied and assume that $i_{*}^{o}>\underline{i}$. Then the following holds:
(i) $C(q)<C^{o}(q)$ if and only if $q<\mathbb{E}[q]\left[\frac{1+i_{*}^{o}}{1+\frac{i_{*}+i_{*}^{o}}{2}}\right]$;
(ii) $\mathbb{E}[C]<\mathbb{E}\left[C^{o}\right]$. 
Assertion (i) states that aggregate consumption in an economy with a simple banking system is lower than in an economy with a sophisticated system for low macroeconomic shocks but higher for shocks sufficiently high above the average shock. Assertion (ii) states that on average, consumption in an economy with a simple banking system is lower than in an economy with a sophisticated system. This efficiency gain is achieved by deterring entrepreneurs with investment projects of a too low quality from applying for loans.

Theorem 5 is illustrated with Figure 2(b). It implies that entrepreneurs as a group are better off in an economy with a sophisticated banking system while households who receive the same returns in both systems are indifferent. Entrepreneurs with intermediate quality levels, however, are worse off with a sophisticated system, because they are not subsidized anymore by high-quality entrepreneurs.

If $i_{*}^{o}=i_{*}=\underline{i}$, both economies produce the same aggregate output and thus ensure the same aggregate consumption $C(q)=C^{o}(q)$ for all shocks $q$. Hence there are no efficiency gains and agents are indifferent between the two systems. By Theorem 2, bank owners, on average, receive lower returns on their equity. Therefore, the sole effect of sophistication in this case is a redistribution of income streams from bank owners to entrepreneurs with high quality projects.

The quality level $i_{\mathrm{ER}}$ which describes the fraction of entrepreneurs benefiting from sophistication is, in essence, determined by the distribution of the macroeconomic shocks. ${ }^{13}$ This quality level in turn stipulates the break-even value $q_{\mathrm{BE}}$ at which both banking systems accumulate the same amount of second-period equity. The lower $i_{\mathrm{ER}}$ is, that is, the more entrepreneurs are rewarded with lower loan interest rates, the higher $q_{\mathrm{ER}}$ and thus $q_{\mathrm{BE}}$ is. In view of Theorem 4 , this implies that the more entrepreneurs are rewarded the less likely it is that the default probability of the sophisticated banking system is lower than the default probability of the simple system.

Sophistication in banking may thus entail a trade-off between stability and efficiency.

\subsection{Robustness}

The result that a sophisticated banking system accumulates less equity and may have an increased default risk appears to be counterintuitive. Given the efficiency result in Theorem 5, the question arises to which extent the stability result of Theorem 4 is robust.

A distinctive feature of our equilibrium concept is that banks do not invest into the alternative asset, although they are indifferent between granting loans and the alternative asset when the expected return on equity is equal to $r_{A}$. This indifference is caused by

\footnotetext{
${ }^{13}$ This fact is reflected by eq. (57) in the proof of Theorem 3 below.
} 
our simplifying assumption that raising funds is costless for banks. In the presence of intermediation costs this effect vanishes and offering loans becomes more profitable than the alternative asset. To see this, suppose that the cost of collecting funds from either depositors or equity holders is $\beta$ per unit $(0<\beta<1)$. Suppose, in addition, that these costs have to be paid immediately. ${ }^{14}$ For a simple banking system this would imply that the balance equation (16) has to change to

$$
\left(\eta-i_{*}\right) I=(1-\beta)\left(\bar{S}+d_{*}\right)
$$

In a competitive equilibrium with positive intermediation costs, this would raise the quality level of the marginal entrepreneur and the loan interest rate, as banks have less funds to finance entrepreneurs. Assume, hypothetically, that in such a modified competitive equilibrium, bank $j$ issues the amount of $e$ units of equity in addition to its equity $d_{*}^{j}$ needed to finance entrepreneurs and invests $e$ into the alternative asset. Since equilibrium interest rates will not alter, bank $j$ 's total return on equity computes as

$$
g_{*}^{j}=\frac{\mathbb{E}\left[G_{*}^{j}\right]+(1-\beta) e\left(1+r_{A}\right)}{d_{*}^{j}+e}-1=\frac{d_{*}^{j}}{d_{*}^{j}+e}\left(1+g_{*}\right)+\frac{(1-\beta) e}{d_{*}^{j}+e}\left(1+r_{A}\right)-1
$$

with $g_{*}$ denoting the equilibrium return on equity of banks which grant loans only. Since $g_{*} \geq r_{A}$, it follows that $g_{*}^{j}<g_{*}$. Hence the derivation by bank $j$ is not profitable. A similar argument holds for sophisticated banks. This shows that in our setup risk-neutrality precludes banks from investing into the alternative asset when collecting equity is costly.

A second distinctive feature of our stability result rests on the assumption that the demand for loans above the marginal entrepreneur is inelastic as the loan size $I$ is constant. If, however, a substantial shift in the demand of loans for high-quality entrepreneurs were to occur due to more favorable contracts this would change. Indeed, if the fraction of high-quality entrepreneurs with low default probabilities would increase sufficiently, the default probability of sophisticated banks could become lower than the default probability of the simple banking system.

Finally, a further analysis regarding welfare and income-distributional consequences of sophistication in rating depends on how banks are bailed out in case they default. Let us briefly discuss two scenarios. Suppose first that the current generation bears the cost of the bail-out. This implies that the current generation has to provide rescue funds in case of a bank default which allow banks to at least partially pay back depositors. A priori, consumers in such a scenario tend to be worse off with a sophisticated banking system

\footnotetext{
${ }^{14}$ In practice these costs will vary across different sources of funding and across assets. The argument presented here carries over to heterogeneous costs.
} 
should they have to contribute to rescue funds while the effect on entrepreneurs appears to be ambiguous. If bail-out schemes are anticipated by agents, their decision problems have to be adapted before a welfare analysis can be conducted. This is left for future research.

Second, suppose that banks are bailed out by future (unmodeled) generations. This scenario is well-known in the banking crises literature when countries responded to largescale banking problems by drastically lowering short-term interest rates. This may generate large profits for banks and may thus allow them to recover gradually (see e.g. Hellman, Murdock \& Stiglitz (2000) and Hoshi \& Kashyap 2004). Under such circumstances, the current generation in our model does not bear the cost of a bail-out. As expected aggregate consumption of the current generation is higher in a sophisticated system, so is their aggregate welfare as the utilitarian sum of all utilities. Future generations which bear the costs of a bail-out are worse off. A complete welfare analysis, however, calls for a fully fledged OLG model and must be left for future research.

\section{Conclusions}

We have shown that sophistication in risk management which prices in the default risk of entrepreneurs benefits high-quality entrepreneurs by lowering loan rates and reducing cross-subsidization of intermediate-quality entrepreneurs. Sophisticated banks reduce the credit access of entrepreneurs with intermediate-quality levels and attract less equity than simple banks. As a consequence, expected repayments to the simple banking system are higher and its default risk may be lower. We have also shown that an economy with a sophisticated banking system invests its funds more efficiently leading to a higher expected aggregate consumption. This trade-off between efficiency and stability of a banking system may be a serious concern for bank regulation. In future research we will investigate the extent to which these results are robust and what the consequences for possible bail-out policies are.

\section{A Appendix}

\section{Proof of Proposition 1.}

Step 1. We determine the relationship between interest rates and quality levels that makes an entrepreneur indifferent between investing into production and into the alternative asset. Set

$$
r_{\max }^{c}:=\frac{\bar{q}(1+\eta) f}{I}-1
$$


where $\bar{q}$ denotes the highest possible shock. Then the expected profit (1) of entrepreneur $i$ is zero, i.e., $\Pi\left(i, r^{c}\right)=0$ for $r^{c} \geq r_{\max }^{c}$. Consider the condition

$$
\Pi\left(i, r^{c}\right)-W\left(1+r_{A}\right) \stackrel{!}{=} 0, \quad i \in[\underline{i}, \eta]
$$

It follows from the first assumption in the proposition that for each $i \in[\underline{i}, \eta]$,

$$
\Pi(i, 0) \geq \Pi(\underline{i}, 0)>W\left(1+r_{A}\right)>\Pi\left(i, r_{\max }^{c}\right)=0 .
$$

Hence equation (48) has a solution $r^{c}=\varphi(i)$ such that

$$
\Pi(i, \varphi(i))-W\left(1+r_{A}\right)=0 \text { for all } i \in[\underline{i}, \eta] .
$$

Since $\Pi\left(i, r^{c}\right)$ is continuous and strictly increasing in $i$, this solution is uniquely determined. Since $\Pi\left(i, r^{c}\right)$ is decreasing in $r^{c} \in\left[0, r_{\max }^{c}\right], \varphi$ is increasing in $i$.

Step 2. Consider the function $F:[\underline{i}, \eta] \rightarrow \mathbb{R}$, defined by

$$
F(i):=\frac{1}{(\eta-i)} \int_{i}^{\eta} \mathcal{R}\left(i^{\prime}, \varphi\left(i^{\prime}\right)\right) \mathrm{d} i^{\prime}-I\left(1+r_{A}\right) .
$$

Using (13) and Condition (16), Condition (15) as an equality takes the form $F\left(i_{*}\right) \stackrel{!}{=} 0$. Observe that for each $r^{c} \geq 0$,

$$
\Pi\left(i, r^{c}\right)+\mathcal{R}\left(i, r^{c}\right)=\mathbb{E}[q](1+i) f, \quad i \in[0, \eta]
$$

Integrating (51) implies

$$
\int_{i}^{\eta}\left[\mathcal{R}\left(i^{\prime}, \varphi\left(i^{\prime}\right)\right)+\Pi\left(i^{\prime}, \varphi\left(i^{\prime}\right)\right)\right] \mathrm{d} i^{\prime}=(\eta-i) \mathbb{E}[q] f\left[1+\frac{i+\eta}{2}\right] .
$$

Using (49) yields

$$
\frac{1}{(\eta-i)} \int_{i}^{\eta} \mathcal{R}\left(i^{\prime}, \varphi\left(i^{\prime}\right)\right) \mathrm{d} i^{\prime}=\mathbb{E}[q] f\left[1+\frac{i+\eta}{2}\right]-W\left(1+r_{A}\right)
$$

The assumption on the average productivity of entrepreneurs applied to (52) then implies $F(\underline{i})<0<F(\bar{i})$. By continuity of $F$, there exists $i_{*}$ such that $F\left(i_{*}\right)=0$. We infer from Step 1 that $F(i)$ is increasing so that $i_{*}$ is uniquely determined. Clearly, $r_{*}^{c}=\varphi\left(i_{*}\right)$ and since by construction $\underline{i}<i_{*}<\bar{i}$, Conditions (14) and (17) are satisfied with $d_{\mathrm{reg}}<d_{*}<$ $i_{*} W$.

Step 3. We show uniqueness of the equilibrium determined in Step 2. Suppose that an additional equilibrium $\left(\underline{i}, \underline{i} W, \tilde{r}_{*}^{c}\right)$ without investment into the alternative asset exists. This equilibrium has to satisfy (14). A straightforward calculation shows that $F(\underline{i})<0$ 
implies $g(\underline{i}, \varphi(\underline{i}))<r_{A}$. Thus $W[1+g(\underline{i}, \varphi(\underline{i}))]<W\left(1+r_{A}\right)=\Pi(\underline{i}, \varphi(\underline{i}))$. Since $g$ is increasing and $\Pi$ is decreasing with respect to $r^{c}$, we have $\tilde{r}_{*}^{c}>\varphi(\underline{i})$. Hence

$$
W\left[1+g\left(\underline{i}, \tilde{r}_{*}^{c}\right)\right]=\Pi\left(\underline{i}, \tilde{r}_{*}^{c}\right)<W\left(1+r_{A}\right)
$$

which contradicts (15). This completes the first part of the proof.

Step 4. As for the second part notice first that the assumption on the average productivity implies $F(\underline{i}) \geq 0$. Thus $g(\underline{i}, \varphi(\underline{i})) \geq r_{A}$ and

$$
W[1+g(\underline{i}, \varphi(\underline{i}))] \geq W\left(1+r_{A}\right)=\Pi(\underline{i}, \varphi(\underline{i})) .
$$

On the other hand, using (13) and (16) as well as the assumption on $\Pi(\underline{i}, 0)$, we have

$$
\underline{i} W[1+g(\underline{i}, 0)] \leq(\eta-\underline{i}) I-\bar{S}\left(1+r_{A}\right) \leq \underline{i} W\left(1+r_{A}\right)<\underline{i} \Pi(\underline{i}, 0)
$$

The monotonicity properties of $g$ and $\Pi$ now imply the existence of a unique $0<r_{*}^{c} \leq \varphi(\underline{i})$ such that $W\left[1+g\left(\underline{i}, r_{*}^{c}\right)\right]=\Pi\left(\underline{i}, r_{*}^{c}\right)$. Since $r_{*}^{c} \leq \varphi(\underline{i})$, we have $g\left(\underline{i}, r_{*}^{c}\right) \geq r_{A}$.

\section{Proof of Proposition 2.}

By assumption, we have $G_{*}(\underline{q})<0$. Since $G_{*}(q)>0$ for $q \geq q_{\mathrm{NB}}$ and since the function $G_{*}$ is continuous and strictly increasing in $q$, there exists a unique critical shock $\underline{q}<q_{\text {crit }}<q_{\mathrm{NB}}$ so that $G_{*}\left(q_{\text {crit }}\right)=0$.

\section{Proof of Proposition 3.}

Step 1. Adding the equilibrium conditions (28) and (32), we get

$$
\Pi\left(i_{*}^{o}, r^{c}\right)+\mathcal{R}\left(i_{*}^{o}, r^{c}\right)=(W+I)\left(1+r_{A}\right)
$$

for all $r^{c} \geq 0$. Using (51) and solving for $i_{*}^{o}$, yields

$$
1+i_{*}^{o}=\frac{(W+I)\left(1+r_{A}\right)}{\mathbb{E}[q] f} .
$$

Hence, by construction, there exists a unique $i_{*}^{0}$ with $\underline{i}<i_{*}^{o}<\bar{i}$. Setting $r_{i_{*}^{o}}^{c o}=\varphi\left(i_{*}^{o}\right)$ with $\varphi$ as defined in (49), Condition (28) holds by construction. Condition (32) follows from subtracting (28) from (53). Moreover, Condition (31) is satisfied with $d_{\mathrm{reg}}<d_{*}^{o}<i_{*}^{o} W$.

Step 2. Uniqueness of equilibria. Observe that $\mathbb{E}[q] f(1+\underline{i})<(W+I)\left(1+r_{A}\right)$ is equivalent to $g^{o}(\underline{i}, \varphi(\underline{i}))<r_{A}$. The uniqueness of an equilibrium with $i_{*}^{o}>\underline{i}$ then follows analogously 
to Step 3 of Proposition 1. If, on the contrary $\mathbb{E}[q] f(1+\underline{i}) \geq(W+I)\left(1+r_{A}\right)$, a reasoning analogously to Step 4 of Proposition 1 shows the uniqueness of an equilibrium with $i_{*}^{o}=\underline{i}$. Step 3. We show that (27) is satisfied. From the equilibrium conditions (28) and (29) we infer $\Pi\left(i_{*}^{o}, r_{i_{*}^{o}}^{c o}\right)>0$. This implies

$$
\bar{q}(1+i) f>I\left(1+r_{i_{*}^{o}}^{c}\right) \quad \text { for all } i \in\left[i_{*}^{o}, \eta\right]
$$

Notice that $\mathcal{R}\left(i, r^{c}\right)$ is strictly increasing in $r^{c}$ as long as $\bar{q}(1+i) f>I\left(1+r^{c}\right)$ and strictly increasing in $i$ as long as $\underline{q}(1+i) f<I\left(1+r^{c}\right)$. This implies the existence of a unique non-increasing function $r_{*}^{c o}(i), i \in\left[i_{*}^{o}, \eta\right]$ with $r_{*}^{c o}\left(i_{*}^{o}\right)=r_{i_{*}^{o}}^{c}$ such that

$$
\mathcal{R}\left(i, r_{*}^{c o}(i)\right)=\mathcal{R}\left(i_{*}^{o}, r_{i_{*}^{o}}^{c}\right), \quad i \in\left[i_{*}^{o}, \eta\right] .
$$

Thus Condition (27) is satisfied.

Step 4. We need to define $r_{*}^{c o}(i)$ for all quality levels $i \in[0, \eta]$. Notice that $r_{*}^{c o}(i)$ can be defined via (55) for all $i \geq 0$ that satisfy $\mathbb{E}[q](1+i) f \geq \mathcal{R}\left(i_{*}^{o}, r_{i_{*}^{o}}^{c}\right)$. If there exists $i_{\text {low }} \geq 0$ such that $\mathbb{E}[q]\left(1+i_{\text {low }}\right) f=\mathcal{R}\left(i_{*}^{o}, r_{i_{*}^{o}}^{c}\right)$, then setting $r_{*}^{c o}(i)=r_{*}^{c o}\left(i_{\text {low }}\right)$ for all $i \in\left[0, i_{\text {low }}\right]$, the function $r_{*}^{c o}(i)$ is extended to a non-increasing function on all of $[0, \eta]$. Clearly, $i \mapsto r_{*}^{c o}(i)$ is continuous on $[0, \eta]$ since $\mathcal{R}$ is continuous. Hence

$$
\Pi\left(i, r_{*}^{c o}(i)\right)<W\left[1+g\left(i_{*}^{o}, r_{i_{*}^{o}}^{c}\right)\right], \quad \text { for all } i \in\left[0, i_{*}^{o}\right),
$$

showing that all entrepreneurs $i<i_{*}^{o}$ either provide equity or invest into the alternative asset, whereas all entrepreneurs $i \geq i_{*}^{o}$ invest into their production project.

\section{Proof of Corollary 1.}

Since $\mathcal{R}\left(i, r^{c}\right)$ is increasing in $r^{c}$ as long as $\bar{q}(1+i) f>I\left[1+r^{c}\right]$, the loan interest function $r_{*}^{c o}(i)$ is decreasing unless there exists $i_{\mathrm{NB}} \in\left[i_{*}^{o}, \eta\right]$ such that $\underline{q}\left(1+i_{\mathrm{NB}}\right) f=I\left[1+r_{*}^{c o}\left(i_{\mathrm{NB}}\right)\right]$ In this case it follows from (32) that $r_{*}^{c o}(i)=r_{A}$ for all $i \geq i_{\mathrm{NB}}$.

\section{Proof of Theorem 1.}

It follows from the proofs of Propositions 1 and 3 that the two marginal entrepreneurs $i_{*}^{o}>\underline{i}$ and $i_{*}>\underline{i}$ are given by the condition $\mathcal{R}\left(i_{*}^{o}, \varphi\left(i_{*}^{o}\right)\right)=I\left(1+r_{A}\right)$ and condition $F\left(i_{*}\right)=0$, respectively, where $F$ as defined in (50). Since by (12)

$$
(\eta-i) \mathcal{R}\left(i, r^{c}\right)<\mathbb{E}\left[P\left(\cdot, i, r^{c}\right)\right], \quad i \in[\underline{i}, \eta), \quad r^{c} \geq 0
$$


it follows that $i_{*}^{o}>i_{*}$. If $i_{*}=\underline{i}$, this inequality holds by assumption. This proves the first claim. The second claim follows directly from (16) and (30) yielding $d_{*}^{o}<d_{*}$. The third claim is an immediate consequence of the first two assertions.

\section{Proof of Theorem 2.}

Using (56), we see that $g\left(\underline{i}, r^{c}\right)>g^{o}\left(\underline{i}, r^{c}\right)$ for all $r^{c} \geq 0$. The equilibrium conditions (14) and $(28)$ then imply $r_{*}^{c o}(\underline{i})>r_{*}^{c}$. Hence $\mathbb{E}\left[P_{*}\right]>\mathbb{E}\left[P_{*}^{o}\right]$ yielding the claim.

\section{Proof of Theorem 3.}

Step 1. Let $i_{*}>\underline{i}$. By the mean value theorem for integrals, there exists $i_{\mathrm{ER}} \in\left[i_{*}, \eta\right]$ such that

$$
\mathbb{E}\left[P_{*}\right]=\int_{i_{*}}^{\eta} \mathcal{R}\left(i, r_{*}^{c}\right) \mathrm{d} i=\left(\eta-i_{*}\right) \mathcal{R}\left(i_{\mathrm{ER}}, r_{*}^{c}\right) .
$$

Since $\underline{q}\left(1+i_{*}\right) f<I\left(1+r_{*}^{c}\right)$ by assumption, $\mathcal{R}\left(i, r_{*}^{c}\right)$ is increasing with respect to $i$ at least locally around $i_{*}$ and otherwise non-decreasing in $i$. Hence $i_{\mathrm{ER}} \in\left(i_{*}, \eta\right)$. Now (18) and (57) imply $\mathcal{R}\left(i_{\mathrm{ER}}, r_{*}^{c}\right)=I\left(1+r_{A}\right)$ such that $r_{*}^{c o}\left(i_{\mathrm{ER}}\right)=r_{*}^{c}$ by construction of a sophisticated equilibrium. Since $i_{\mathrm{ER}}>i_{*}$, we have

$$
\Pi\left(i_{\mathrm{ER}}, r_{*}^{c}\right)>\Pi\left(i_{*}, r_{*}^{c}\right)=W\left(1+r_{A}\right)=\Pi\left(i_{*}^{o}, r_{*}^{c o}\left(i_{*}^{o}\right)\right)
$$

and thus $i_{\mathrm{ER}}>i_{*}^{o}$. Hence $i_{\mathrm{ER}} \in\left(i_{*}^{o}, \eta\right)$. By Assumption 1, $i_{*}$ has a positive default risk which implies $r_{*}^{c o}\left(i_{\mathrm{E} R}\right)>r_{A}$. Hence $r_{*}^{c o}(i)$ must be decreasing locally around $i_{\mathrm{ER}}$ by Corollary 1.

Step 2. Let $i_{*}^{o}=i_{*}=\underline{i}$. From the proof of Theorem 2 we know that $r_{*}^{c o}(\underline{i})>r_{*}^{c}$ and $\mathbb{E}\left[P_{*}\right]>\mathbb{E}\left[P_{*}^{o}\right]$. This together with $i_{*}^{o}=i_{*}$ implies the existence of $i_{\mathrm{ER}} \in(\underline{i}, \eta)$ with the above properties.

\section{Proof of Theorem 4.}

(i) Since both systems face a positive default risk, $\bar{S}\left(1+r_{A}\right)>P_{*}(\underline{q}) \geq P_{*}^{o}(\underline{q})$. On the other hand $P_{*}\left(q_{\mathrm{BE}}\right) \geq P_{*}^{o}\left(q_{\mathrm{BE}}\right)>\bar{S}\left(1+r_{A}\right)$. Since $P_{*}$ and $P_{*}^{o}$ are increasing in $q$, it follows from Propositions 5 and 6 that $q_{\text {crit }}<q_{\text {crit }}^{o}$, where the critical values $q_{\text {crit }}$ and $q_{\text {crit }}^{o}$ are given by

$$
P_{*}\left(q_{\text {crit }}\right)=P_{*}^{o}\left(q_{\text {crit }}^{o}\right)=\bar{S}\left(1+r_{A}\right)
$$


Recalling the definitions of the default probabilities (24) and (40), this proves (i).

(ii) In this case we have $P_{*}\left(q_{\mathrm{BE}}\right) \leq P_{*}^{o}\left(q_{\mathrm{BE}}\right)<\bar{S}\left(1+r_{A}\right)$. Since $P_{*}$ and $P_{*}^{o}$ are increasing in $q$, it follows from Propositions 5 and 6 that $q_{\text {crit }}>q_{\text {crit }}^{o}$. This proves (ii).

\section{Proof of Theorem 5.}

(i) Computing the respective integrals for entrepreneurial output, one has

$$
Y(q)=q f\left[\eta-i_{*}+\frac{1}{2}\left(\eta^{2}-i_{*}^{2}\right)\right]
$$

and

$$
Y^{o}(q)=q f\left[\eta-i_{*}^{o}+\frac{1}{2}\left(\eta^{2}-\left(i_{*}^{o}\right)^{2}\right)\right]
$$

On the other hand, the balance equations imply

$$
i_{*} W-d_{*}=i_{*}(W+I)-\eta I+\bar{S}
$$

and

$$
i_{*}^{o} W-d_{*}^{o}=i_{*}^{o}(W+I)-\eta I+\bar{S} .
$$

Inserting equations (58) to (61), we see that $C(q)<C^{o}(q)$ if and only if

$$
q\left(1+\frac{i_{*}+i_{*}^{o}}{2}\right) f<(W+I)\left(1+r_{A}\right)
$$

Using (51), in a sophisticated equilibrium

$$
\mathbb{E}[q]\left(1+i_{*}^{o}\right) f=\Pi\left(i_{*}^{o}, r_{*}^{c o}\left(i_{*}^{o}\right)\right)+\mathcal{R}\left(i_{*}^{o}, r_{*}^{c o}\left(i_{*}^{o}\right)\right)=(W+I)\left(1+r_{A}\right) .
$$

Inserting (63) into (62), we see that Assertion (i) holds

(ii) Taking expectations, it follows from a reasoning analgous to part (i) that $\mathbb{E}[C]<$ $\mathbb{E}\left[C^{o}\right]$ if and only if

$$
\mathbb{E}[q]\left(1+\frac{i_{*}+i_{*}^{o}}{2}\right) f<(W+I)\left(1+r_{A}\right) .
$$

Since by Theorem 3 (i) $i_{*}<i_{*}^{o}$, Assertion (ii) follows from (63). 


\section{References}

Al-NajJaR, N. I. (1995): "Decomposition and Characterization of Risk with a Continuum of Random Variables", Econometrica, 63, 1195-1224.

Alós-Ferrer, C. (1999): "Individual Randomness in Economic Models with a Continuum of Agents", Working paper no. 9807, University of Vienna.

Bester, H. (1985): "Screening versus Rationing in Credit Markets with Imperfect Competition", American Economic Review, 75(4), 850-855.

(1987): "The Role of Collateral in Credit Markets with Imperfect Information", European Economic Review, 31(4), 887-899.

Bhattacharya, S., A. Boot \& A. V. Thakor (1998): "The Economics of Bank Regulation", Journal of Money Credit and Banking, 30(4), 745-770.

Bhattacharya, S. \& A. V. Thakor (1993): "Contemporary Banking Theory", Journal of Financial Intermediation, 3, 2-50.

Carey, M. \& R. Stulz (eds.) (2006): The Risks of Financial Institutions. University of Chicago Press, forthcoming.

Dewatripont, M. \& J. Tirole (1994): The Prudential Regulation of Banks. MIT Press.

DiAmond, D. (1984): "Financial Intermediation and Delegated Monitoring", Review of Economic Studies, 51, 393-414.

Franke, G. \& J. Krahnen (2006): "Default Risk Sharing Between Banks and Markets: The Contribution of Collateralized Debt Obligations", in The Risks of Financial Institutions, ed. by M. Carey \& R. Stulz. University of Chicago Press, forthcoming.

Freixas, X. \& J.-C. Rochet (2008): Microeconomics of Banking. MIT Press, Cambridge, MA.

Gehrig, T. \& R. Stenbacka (2004): "Screening Cycles", Working paper, University of Freiburg.

Gersbach, H. \& H. Uhlig (2005): "Debt Contracts and Collapse as Competition Phenomena", Forthcoming Journal of Financial Intermediation. 
Gersbach, H. \& J. Wenzelburger (2004): "Do risk premia protect from banking crises?", Discussion Paper No. 519, Bielefeld University and CEPR Discussion Paper No. 4935.

(2006): "Sophistication in Risk Management and Banking Stability: The Short Term", Discussion Paper 550, Department of Economics, University of Bielefeld.

Hellman, T., K. Murdock \& J. Stiglitz (2000): "Liberalization, Moral Hazard in Banking, and Prudential Regulation: Are Capital Requirements Enough?", American Economic Review, 90(1).

Hellwig, M. F. (1994): "Banking and Finance at the End of the Twentieth Century", WWZ-Discussion paper no. 9426, University of Basel.

Hoshi, T. \& A. Kashyap (2004): "Japan's Economic and Financial Crisis: An Overview", The Journal of Economic Perspective, forthcoming.

Krahnen, J. \& M. Weber (2001): “Generally Accepted Rating Principles: A Primer", Journal of Banking \& Finance, 25, 3-24.

Stiglitz, J. E. \& A. Weiss (1981): "Credit Rationing in Markets with Imperfect Information", American Economic Review, 71(3), 393-410.

Uhlig, H. (1996): "A Law of Large Numbers for Large Economies", Economic Theory, $8,41-50$. 